JURNAL CEMERLANG: Pengabdian pada Masyarakat ISSN 2654-4741

Vol. 1, No. 1, 2018, $101-109$

DOI: https://doi.org/10.31540/jpm.v1i1.170

\title{
IMPLEMENTASI APLIKASI "PETANI" DAN "HUKAKU" DALAM UPAYA PENINGKATAN PENGETAHUAN TENTANG PRODUKTIVITAS DAN PENDAPATAN PERTANIAN SAMOSIR SUMATERA UTARA
}

\author{
THF. Harumy, Hanifah ZN. Amrul \\ Universitas Pembangunan Pancabudi, Indonesia
}

\begin{abstract}
ABSTRAK
Permasalahan yang dihadapi oleh petani di Samosir adalah sulit bagi mereka untuk menjual hasil panen mereka dengan harga lebih tinggi. Salah Satu contoh permasalahan, yang dihadapi adalah serangan jamur pada tanaman bawang. Hingga saat ini penanganan kepada para petani dianggap belum maksimal. Solusi yang digunakan dalam upaya mengatasi masalah ini adalah dengan menggunakan aplikasi "HUKAKU" dan aplikasi "PETANI" Aplikasi ini memiliki fitur Toko online, Panen, Forum, Chatting bersama ahli dan lain -lain. Metode yang digunakan pada pengabdian ini adalah melalui layanan pembelajaran yang memberikan pelatihan dan bantuan perangkat lunak bagi petani dalam upaya meningkatkan produktivitas dan pendapatan petani. Hasil dari kegiatan pengabdian ini adalah petani dapat menjualhasil pertanian secara online dalam upaya peningkatan pendapatan dan mendapatkan akses dan komunikasi bersama ahli tentang informasi pertanian dan pengendalian hama sehingga dapat meningkatkan produktivitas pertanian.
\end{abstract}

KEYWORDS

Pertanian, Hukaku, Petani , Pendapatan , Produktivitas

\section{ARTICLE HISTORY}

Received 25 November 2018

Revised 15 December 2018

Accepted 19 December 2018

CORRESPONDENCE THF. Harumy@ hennyfebriana@dosen.pancabudi.ac.id

\section{PENDAHULUAN}

Kabupaten Samosir adalah salah satu lahan pertanian yang cukup potensial di Sumatera Utara dengan luas lahan 146.701 hectare dan luas panen sebesar 22.895 Hectare (BPS 2017). Permasalahan yang dihadapi oleh petani di Samosir adalah sulitnya mereka untuk menjual hasil panen dengan harga yang lebih tinggi. 


\section{JURNAL CEMERLANG: Pengabdian pada Masyarakat}

ISSN 2654-4741

Vol. 1, No. 1, 2018, $101-109$

DOI: https://doi.org/10.31540/jpm.v1i1.170

Selama ini yang dilakukan petani adalah selalu menjual hasil pertanian mereka kepada Toke dengan harga yang telah di tentukan. Masalah selanjutnya yang dihadapipetani adalah serangan jamur pada tanaman Bawang Merah. Sehingga banyak petani yang berhenti menanam tanaman bawang merah yang pada dasarnya adalah produk unggulan dari Kabupaten Samosir. Oleh sebab itulah dibutuhkan suatu solusi untuk pemecahan masalah tersebut. Solusiuntukmengatasi masalah tersebut adalah dengan mengenalkan Aplikasi mobile Lelang "HUKAKU" dan PETANI sehingga petani dapat menjual hasil pertanian dengan harga yang wajar dan bersaing dan dan petani dapat berkomunikasi dan berdiskusi dengan pakar pertanian. Pengabdian difokuskan kepada kelompok tani Mandiri dikarenakan kelompok tani ini memiliki potensi untuk dikembangkan dan harapannya kelompok tani mandiri akan menjadi leader untuk membagikannya kepada kelompok tani yang lain. Aplikasi Mobile pada dasarnya adalah aplikasi yang dapat dijalankan di handphone dan memiliki fungsi untuk mempermudah komunikasi antar sesama user. (Harumy T.H.F., 2018). Saat ini upaya-upaya yang telah dilakukan oleh pihak lain adalah yang dilakukan oleh Penyuluh pertanian dari Dinas Pertanian Kabupaten Samosir. Penyuluhan yang dilakukan adalah bagaimana menanam dengan baik, pemilihan pupuk dan lain-lain. Pada dasarnya potensi Aplikasi Mobile sangat tinggi kepada peningkatan pengetahuan teknologi seperti penerapan aplikasi mobile untuk nelayan (Muhammad Iqbal, Muhammad Zarlis, T.H.F Harumy, 2017), (Henny Febriana Harumy and Tarigan, 2018)

Tujuan Program pengabdian kepada masyarakat ini adalah memberikan solusi sebagai berikut :

1. Mengenalkan Aplikasi Lelang "HUKAKU" dan Aplikasi "PETANI" Petani agar petani mampu menjual lebih tinggi karena menggunakan system lelang sehingga petani bebas menjual hasil pertanian dengan pembeli yang menawarkan harga tertinggi sehingga pendapatan petani tersebut meningkat, dan juga petani dapat berkomunikasi langsung dengan calon pembeli sehingga 


\section{JURNAL CEMERLANG: Pengabdian pada Masyarakat}

ISSN 2654-4741

Vol. 1, No. 1, 2018, $101-109$

DOI: https://doi.org/10.31540/jpm.v1i1.170

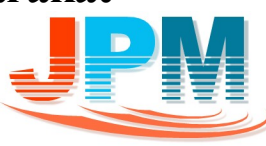

dapat meminimalisir jumlah tengkulak/ Perantara yang dapat memainkan harga yang menguntungkan pihak tengkulak

2. Dengan adanya aplikasi lelang HUKAKU dan PETANI berbasis mobile petani dan tenaga ahli (pakar pertanian) dapat terkoneksi setiap saat sehingga petani yang mengalami kendala seperti hama yang menganggu proses produksi, sulit menentukan pupuk yang terbaik dan permasalahan seputar pertanian lainnya dapat dibantu oleh tenaga ahli yang terhubung di aplikasi.

\section{MASALAH}

Adapun permasalahan yang dialami oleh petani di desa Cinta Dame Kabupaten Samosir adalah sebagai berikut:

1. Petani tidak memiliki pembanding harga, dan rantai distribusi panjang sehingga harga di petani rendah namun harga di konsumen tinggi. Sebagai Petani, mereka sangat bergantung kepada hasil panen dan nilai jual. Saat ini petani di Desa Cinta Dame masih sangat tergantung kepada Toke. Bahkan harga yang ditawarkan oleh Toke kepada Petani sangat bervariasi dan tidak adanya kepastian harga. Seperti jagung kering yang dijual hanya Rp.350,00 per kilonya kepada Toke.

2. Petani dan tenaga ahli tidak tersambung dan tidak terkoneksi setiap saat dan penyuluh juga belum tentu dapat memberikan jawaban dan juga kurangnya informasi budidaya dan hama

3. Diharapkan setelah adanya penerapan dan pengenalan aplikasi ini Petani tidak lagi memiliki ketergantungan kepada toke, dan dapat langsung menjual hasil panen mereka dengan harga yang bersaing.

\section{METODE}

Metode yang digunakan pada pengabdian ini adalah service learning (St. Syamsudduha, 2017) dan pihak-pihak yang terlibat pada kegiatan ini adalah kelompok Tani, Penyuluh Pertanian dan BMKG untuk connecting data cuaca. Bentuk keterlibatan nya adalah dengan ikut mendampingi pada saat proses https://ojs.stkippgri-lubuklinggau.ac.id/index.php/JPM 


\section{JURNAL CEMERLANG: Pengabdian pada Masyarakat}

ISSN 2654-4741

Vol. 1, No. 1, 2018, $101-109$

DOI: https://doi.org/10.31540/jpm.v1i1.170

pelatihan berlangsung. Kegiatan ini dilakukan di Desa Cinta Dame Kabupaten samosir. Proses pendampingan dilakukan selama 6 Bulan dari mulai peneympurnaan dan pengenalan aplikasi sampai dengan implementasi nya kepada petani sejak bulan maret 2018 .

Untuk merealisasikan sistem ini maka dilakukan terlebih dahulu pendekatan kepadamasyarakatmelaluisosisalisasi, baik kepadakelurahan selaku pemangku ataupun kepada kelompok petani sebagai pengguna nantinya. Setelah sosialisasi akan dilakukan pelatihan sebagaiwujud pengenalan software kepada petani. Dalam kegiatan ini juga dilakukan diskusi dan Tanya jawab. Selanjutnya akan dilakukan simulasi terhadap program atau system yang akan diimplementasikan. Agar sistem ini berlanjut akan diadakan pendampingan terhadap kelompok petani tersebut. Pendampingan akan dilkukan oleh tim pelaksana dan juga Dua orang mahasiswa dari sistem komputer Universitas Pembangunan Panca Budi Medan. Prosedur kerj ayang dilakukan selalu saling berintegrasi antara Petani, tenaga ahli, penyuluh, dan juga lembaga pertanian terkaityaituPuskesmas,Dinas perindustriandanPerdagangan,Dinas Pertanian, BMKG dan lain-lain. Seluruh rangkaian prosedur kerja PKM implementasi aplikasi mobile "PETANI" dan Lelang "HUKAKU" dapat dilihat pada gambar dibawah ini:

Degan prosedur kerja sebagai berikut :

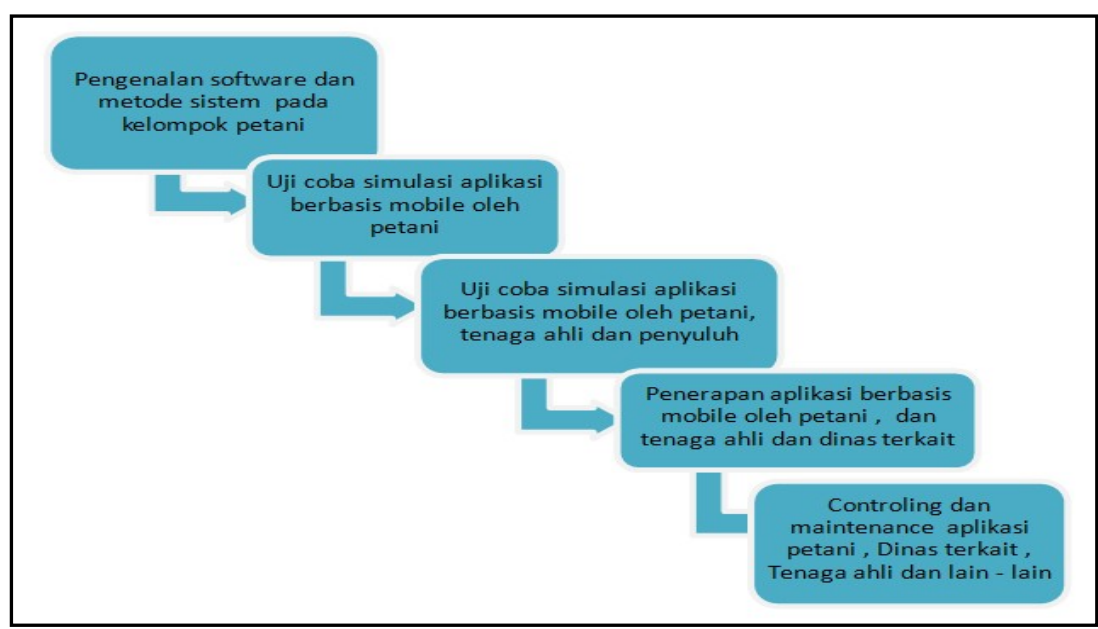

Gambar 1. Prosedur Kerja Pengabdian

https://ojs.stkippgri-lubuklinggau.ac.id/index.php/JPM 


\begin{tabular}{l}
\hline JURNAL CEMERLANG: Pengabdian pada Masyarakat \\
ISSN 2654-4741 \\
Vol. 1, No. 1, 2018, 101-109 \\
DOI: https://doi.org/10.31540/jpm.v1i1.170
\end{tabular}

\section{HASIL DAN PEMBAHASAN}

Bentuk -bentuk kegiatan yang dilakukan adalah dimulai dari pengenalan aplikasi kepada para petani dan dinas terkait. bentuk aplikasi adalah sebagai berikut :
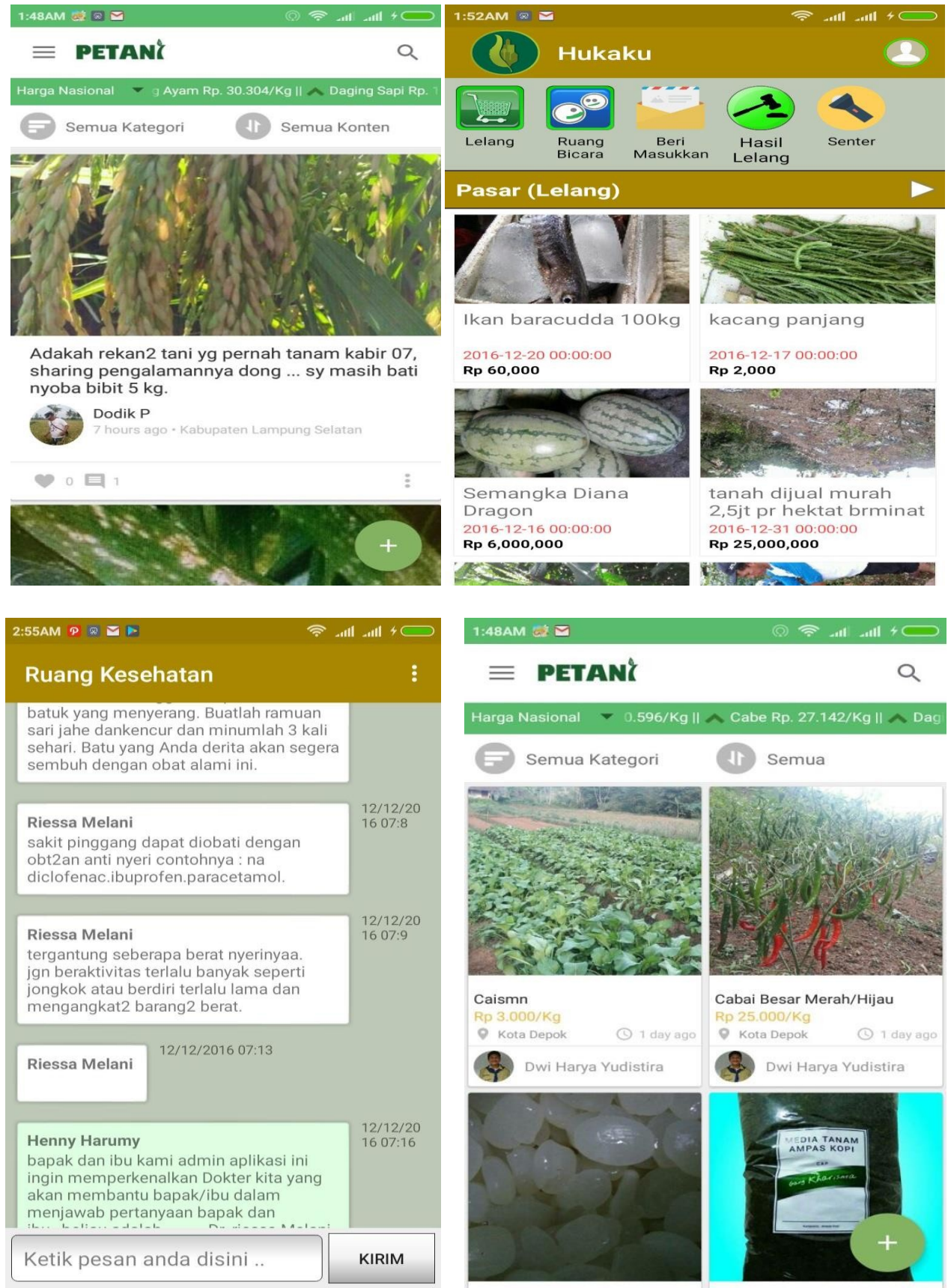

Cabai Besar Merah/Hijau kp 25.000/Kg

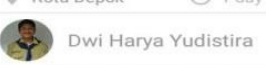

https://ojs.stkippgri-lubuklinggau.ac.id/index.php/JPM 
JURNAL CEMERLANG: Pengabdian pada Masyarakat ISSN 2654-4741

Vol. 1, No. 1, 2018, $101-109$

DOI: https://doi.org/10.31540/jpm.vli1.170

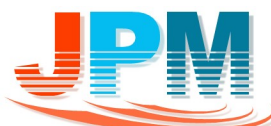

Aplikasi ini memiliki fitur-fitur yang sangat beragam dimulai dari ruang bicara, Lelang, daftar harga pasar nasional, diskusi pertanian dan lain lain.Aplikasi menitik beratkan kepada peningkatan produktivitas dan pendapatan petani. Adapun kegiatan-kegiatan yang dilakukan adalah sebagai berikut :

\section{Pengabdian yang dilaksanakan dimulai dengan pengenalan software.}

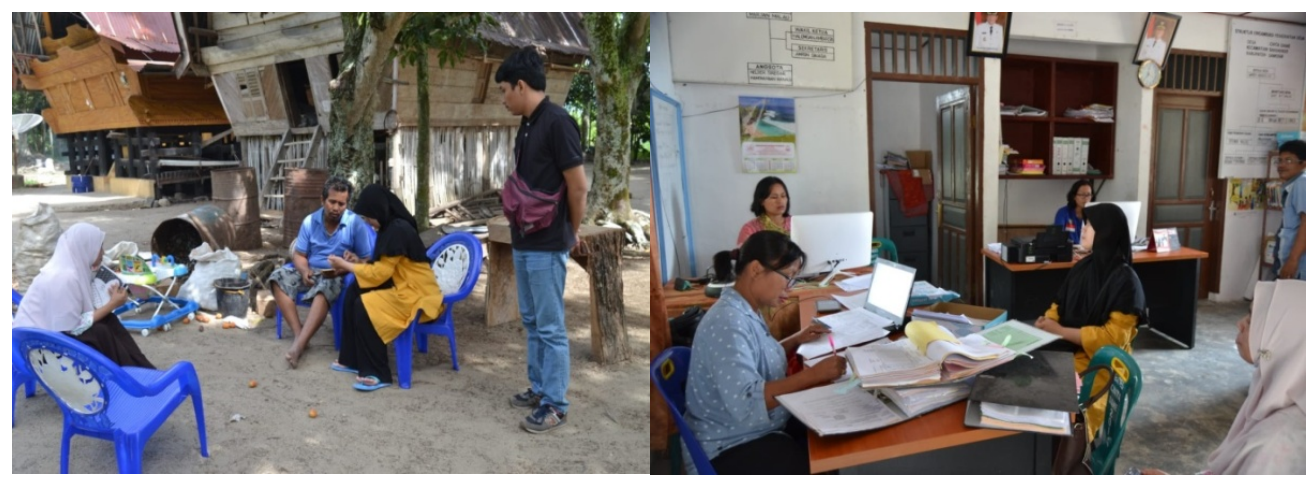

2. Uji coba Simulasi, kepada tenaga ahli dan penyuluh

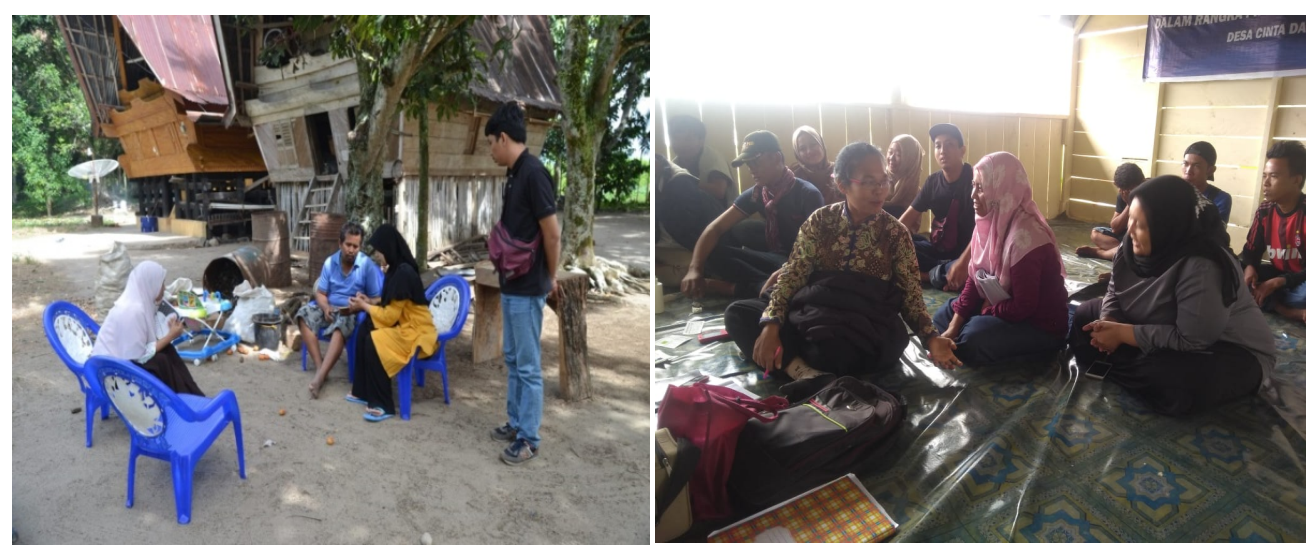

3. Penerapan aplikasi controlling dan maintenance
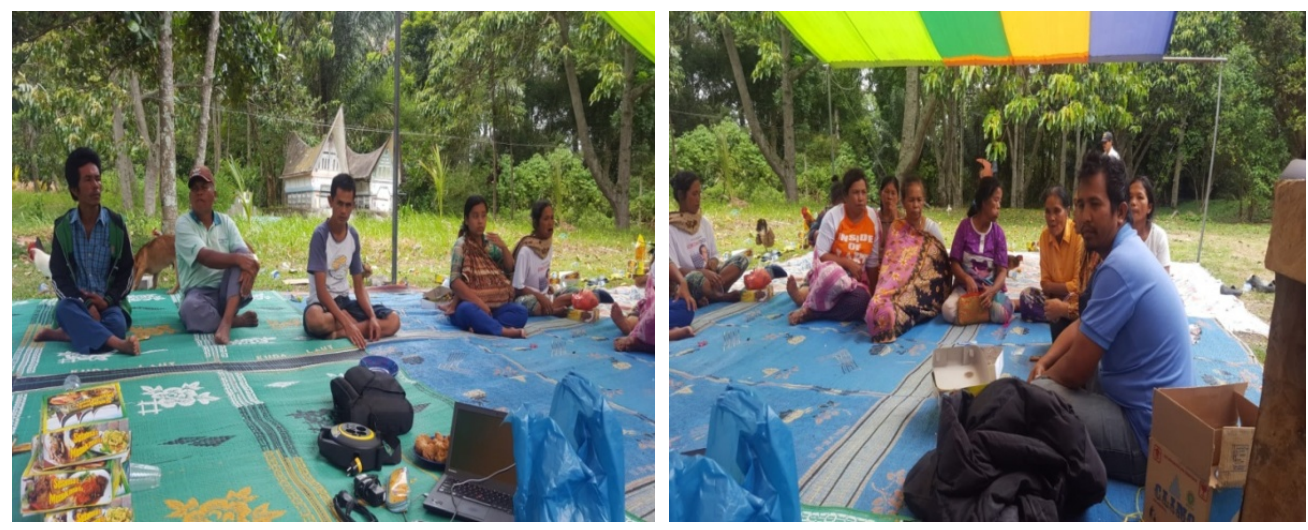

https://ojs.stkippgri-lubuklinggau.ac.id/index.php/JPM 
JURNAL CEMERLANG: Pengabdian pada Masyarakat ISSN 2654-4741

Vol. 1, No. 1, 2018, $101-109$

DOI: https://doi.org/10.31540/jpm.v1i1.170

Kegiatan ini dilakukan selama 6 bulan dimulai dari bulan maret 2018 sampai dengan bulan Agustus 2018. Terdapat beberapa kendala yang dihadapi oleh tim selama proses pendampingan seperti koordinasi dengan dinas terkait dan lain- lain, namun hal tersebut dapat diatasi dengan baik oleh tim.

\section{a. Diskusi kegiatan}

Setelah melakukan kegiatan pengabdian dampak yang dirasakan oleh seluruh pihak yang terkait sangat signifikan. Dimulai dari dampak terhadap penyuluh pertanian, Petani, Dinas terkait dan lain. Dampak yang dirasakan dituangkan kedalam tabel sebagai berikut :

Tabel 1. Dampak Sebelum dan Sesudah kegiatan

\begin{tabular}{|c|c|c|c|}
\hline No & $\begin{array}{l}\text { Pihak } \\
\text { terkait }\end{array}$ & $\begin{array}{l}\text { Dampak Sebelum Penerapan } \\
\text { Aplikasi }\end{array}$ & $\begin{array}{l}\text { Dampak Sesudah Penerapan } \\
\text { Aplikasi }\end{array}$ \\
\hline \multirow[t]{3}{*}{1} & \multirow{3}{*}{ Petani } & $\begin{array}{l}\text { Petani Kesulitan Untuk } \\
\text { Mencari Pembanding Harga, } \\
\text { dan pemutus rantai distribusi } \\
\text { yang panjang sehingga harga } \\
\text { di petani rendah para petani } \\
\text { juga sangat bergantung kepada } \\
\text { hasil panen dan nilai jual. }\end{array}$ & $\begin{array}{l}\text { Aplikasi "Petani" Dan "Hukaku" } \\
\text { Memberikan Kemudahan Kepada } \\
\text { Petani Dengan Fitur } \\
\text { Pembanding Harga yang dan } \\
\text { petani dapat menjual Sendiri } \\
\text { Hasil Panen Dengan Harga Yang } \\
\text { Lebih Tinggi secara online. }\end{array}$ \\
\hline & & $\begin{array}{l}\text { Petani kesulitan berkomunikasi } \\
\text { dan berkonsultasi dengan } \\
\text { tenaga ahli dan penyuluh untuk } \\
\text { masalah penanggulangan hama } \\
\text { dan produktivitas }\end{array}$ & $\begin{array}{l}\text { Petani memiliki kemudahan } \\
\text { untuk berkomunikasi dan } \\
\text { berkonsultasi dengan tenaga ahli } \\
\text { dan penyuluh untuk masalah } \\
\text { penanggulangan hama dan } \\
\text { produktivitas dengan fitur } \\
\text { chatting dan ruang bicara dan } \\
\text { tanya jawab }\end{array}$ \\
\hline & & $\begin{array}{l}\text { Petani Kesulitan Untuk } \\
\text { Mendokumentasikan Hasil } \\
\text { Panen Serta Informasi } \\
\text { Ketersediaan Pupuk } \\
\text { Tersubsidi. }\end{array}$ & $\begin{array}{l}\text { Petani Memiliki Kemudahan } \\
\text { Dengan Fitur "Toko" Untuk } \\
\text { Mendokumentasikan Hasil Panen } \\
\text { Serta Mencari Informasi } \\
\text { Ketersediaan Pupuk Tersubsidi. }\end{array}$ \\
\hline 2 & $\begin{array}{l}\text { (Dinas } \\
\text { Terkait } \\
\text { Pertani } \\
\text { an ) }\end{array}$ & $\begin{array}{l}\text { Belum mengetahui tentang } \\
\text { inovasi aplikasi mobile } \\
\text { HUKAKU dan PETANI . }\end{array}$ & $\begin{array}{l}\text { Membantu Pihak penyuluh untuk } \\
\text { memberikan informasi kepada } \\
\text { petani } \\
\text { Mengenalkan inovasi terbaru } \\
\text { kepada penyuluh dan dinas } \\
\text { terkait tentang aplikasi mobile } \\
\text { HUKAKU dan PETANI . }\end{array}$ \\
\hline
\end{tabular}


JURNAL CEMERLANG: Pengabdian pada Masyarakat ISSN 2654-4741

Vol. 1, No. 1, 2018, $101-109$

DOI: https://doi.org/10.31540/jpm.v1i1.170

\begin{tabular}{|l|l|l|l|}
\hline 3 & Tim & Belum memiliki kedekatan & Dapat mengabdikan pengetahuan \\
& Pengab & kepada petani dan Dinas & teori yang telah di pelajari di \\
& di & Terkait & Kampus dan diimplemntasikan \\
& & $\begin{array}{l}\text { Belum bisa } \\
\text { mengimplementasikan inovasi } \\
\text { yang telah di dapat dari } \\
\text { kampus. }\end{array}$ & \\
& & kepada masyarakat \\
\hline
\end{tabular}

\section{KESIMPULAN}

Kesimpulan dari kegiatan Pengabdian ini adalah Penerapan Aplikasi PETANI dan HUKAKU dapat meningkatkan pengetahuan petani untuk dapat menjual hasil pertanian secara online dalam upaya peningkatan pendapatan dan mendapatkan akses dan komunikasi bersama ahli tentang informasi pertanian dan pengendalian hama sehingga dapat meningkatkan produktivitas pertanian. Rekomendasi dari kegiatan ini adalah diharapkan dinas terkait melakukan pendampingan bagi kelompok-kelompok tani yang lainnya.

\section{UCAPAN TERIMA KASIH}

Ucapan terimakasih Tim ucapkan kepada Kemristekdikti yang telah memberikan dukungan dana melalui program PKM 2018 . selanjutnya adalah Universitas Pembangunan Panca budi dan Kelompok Tani Desa Cinta Dame Simanindo yang telah ikut berpartisipasi dalam kegiatan ini.

\section{DAFTAR PUSTAKA}

Harumy T.H.F., H. M. Z. N. A. (2018) 'Aplikasi Mobile Zagiyan ( Zaringan Digital Nelayan ) Dalam Menunjang Produktivitas Dan Keselamatan, Dan Kesehatan Nelayan', It Journal Research And Developmen, 2(2), Pp. 52-61.

Harumy T.H.F And Tarigan, A. D. (2018) 'Trap (Rumpon) Environment Friendly Based On Microcontroller To Increase Fisherman's Revenue', Journal of Advanced Research In Dynamical And Control Systems, 10(4 Special Issue), Pp. 1576-1580.

Muhammad Iqbal, Muhammad Zarlis, Harumy, T. H.F . . (2017) 'Inovasi Aplikasi Check In Spot Nelayan Untuk Binaan Kecamatan Bagan Deli Medan’, In. 
JURNAL CEMERLANG: Pengabdian pada Masyarakat ISSN 2654-4741

Vol. 1, No. 1, 2018, $101-109$

DOI: https://doi.org/10.31540/jpm.v1i1.170

Jayapura: Seminar Nasional Aptikom (Semnastikom), Pp. 1-6.

St. Syamsudduha, N. Y. T. (2017) 'Penerapan Service Learning Dalam Pembelajaran Matakuliah Pedagogik Pada Kurikulum Pendidikan Calon Guru', Lentera Pendidikan, 20(1), Pp. 1-17.

Bps-A. 2017. Statistik Daerah Kecamatan Laguboti 2017. Badan Pusat Statistik Kabupaten Toba Samosir.

Bps-B.2017. Statistik Daerah Kecamatan Simanindo 2017. Badan Pusat Statistik Kabupaten Samosir.

Muhammad Iqbal, Muhammad Zarlis, Harumy, T. H. F . (2017) 'Inovasi Aplikasi Check In Spot Nelayan Untuk Binaan Kecamatan Bagan Deli Medan', In. Jayapura: Seminar Nasional Aptikom (Semnastikom), Pp. 1-6.

St. Syamsudduha, N. Y. T. (2017) 'Penerapan service learning dalam pembelajaran matakuliah pedagogik pada kurikulum pendidikan calon guru', Lentera pendidikan, 20(1), pp. 1-17. 